\title{
The Interplay of Motivation and Quality of Instructions in the Self-Paced Program: A MOOC for Administration Staffs
}

\author{
Daniel Ginting ${ }^{1}$, Fahmi ${ }^{2}$, Nindya Juwita Utimadini ${ }^{3}$, Rahmah Purwahida ${ }^{4}$, Yusawinur Barella ${ }^{5}$, Husnul Khatimah ${ }^{6}$ \\ ${ }^{1}$ Universitas Ma Chung, Indonesia \\ ${ }^{2}$ Universitas Ahmad Dahlan, Indonesia \\ ${ }^{3}$ Institut Agama Islam Negeri Pontianak, Indonesia \\ ${ }^{4}$ Universitas Negeri Jakarta, Indonesia \\ ${ }^{5}$ Universitas Tanjungpura, Indonesia \\ ${ }^{6}$ Institut Agama Islam Negeri Langsa, Indonesia \\ Correspondence: Daniel Ginting, Universitas Ma Chung, Indonesia.
}

Received: December 21, 2021

doi:10.5430/wjel.v12n1p198

\author{
Accepted: February 17, $2022 \quad$ Online Published: February 23, 2022 \\ URL: https://doi.org/10.5430/wjel.v12n1p198
}

\begin{abstract}
A MOOC has disrupted traditional learning methods. With electronic gadgets and internet support, this online learning platform enables many participants to access abundant learning materials and other instructional resources for free. This paper aims to present a sketch of the relationship between the online participants' motivation with MOOC quality. Involving about ninety-five participants from the university administration staff, the authors have divided them into three groups: high achievers (HA), middle achievers (MA), and low achievers (LA). This study has found that motivation significantly influences active participation in the MOOC program. The MOOC design quality also affects the participants' perception upon completing the MOOC. This study suggests that MOOC designers should develop relevant instructional materials and adjust the difficulty level in the MOOC's contents to enhance meaningful learning.
\end{abstract}

Keywords: multimedia, cognitive load, MOOC, self-paced program

\section{Introduction}

Massive Online Open Course (MOOC) is the technology that gains the spotlight during the actualization of e-learning. MOOC allows online learners to access the course anywhere and anytime. Swan (2005) emphasizes MOOC benefits along with promoting equality in education. MOOC is also beneficial as it succeeded in meeting the Higher Educational demands. Chun et al. (2016) describe that MOOC is potential to allow educators to design their virtual room. Lim (2004) and Chen (2012) claimed that motivation is a vital factor that affects learning quality. Without motivation, it is difficult for learners to achieve competence in the long term.

Dörnyei (2001) describes motivation as a process in which a specific amount of instigation force emerges, initiates action, and endures unless another force intervenes to weaken it and end the activity, or until people achieve the desired result. According to Schunk et al. (2008), motivation is a process of action driving people to achieve goals. Eccles-Parsons, et al. (1983) elaborate motivation and mention three categories driving people to act: attainment value, intrinsic value, and utility value. Students with strong motivation have better performance than students with low motivation (Gardner, 2006). Garcia and Pintrich (1996) have pointed out e-learning behaviors correlated to autonomous behavior or the ability to take self-initiative.

Autonomous learners focus on goals, task values, and self-efficacy. They feel confident about themselves to handle the tasks. The more motivated the learners are, the more autonomous they become. As a result, autonomous people will put great effort into processing information effectively, employ learning strategies, and take on all study tasks (Ginting et al., 2020). The study by Garcia and Pintrich (1996) is in agreement with Kim and Frick's (2011). The latter have found that motivation during self-directed e-learning is the best predictor of positive change in learning improvement. Moreover, motivation also predicts learners' satisfaction with self-directed e-learning. Martens et al. (2004), Rovai et al. (2007), Shroff et al. (2007), Xie et al. (2006) have discussed the importance of self-directed e-learning in online classes. Ginting et al. (2020) added that people's cultural backgrounds affect self-directed 
attitudes or autonomous behaviors. The participants from Indonesia still find it challenging to apply their autonomous attitudes to the MOOC. The online participants get used to waiting for instructions from the instructors. As a result, many participants failed to complete the MOOC. Regardless of the types of instructional delivery, student motivation remains a major concern for educators.

Interestingly, some other studies (Rovai et al., 2007; Shroff et al., 2007; Wighting et al., 2008) have presented some inconsistency regarding the impacts of motivation in online learning. Zhao and Mei (2016) discovered that online learners' motivation is influenced by their gender, employment situation, and marital status. According to Xiong and Zuo (2019), the learning motivation of adult learners differs depending on their age and gender. Solving difficulties, gaining knowledge, increasing cognition, having fun, helping others, and making social contacts are all reasons for them to take online classes. Meanwhile, Deci et al. (2001) mention that autonomous students still rely on external environments. More autonomous types of motivation will be promoted if environmental factors favor an individual's autonomy (Deci \& Ryan, 1985). Tseng and Tsai (2010), Alkis and Temizel (2018), and Bandura (1997) mention that the motivation of the participants to learn online is associated with self-efficacy and the ability of the facilitator to encourage cooperation among all participants through peer review activities. Chaiprasurt and Esichaikul (2013) have said that media plays a crucial role in increasing student motivation to learn online, especially in terms of the attention and engagement variables. Alkis and Temizel (2018) have found that familiarity with online learning impacts their self-efficacy. Shin (2010) mentions several factors affecting students' learning motivation, such as rational conditions, the value of the course, interest in the course, self-determination, and autonomous regulation. Shin's findings are consistent with Xie and Huang's study (2014), demonstrating that scientific and learning beliefs impact students' learning involvement and perceived learning via goals mediation accomplishment. The facilitator's active role also influenced students' active participation in online learning. Xu and Du (2013) found that facilitators should enhance participants' active participation in online learning. Facilitators' regular feedback affects online participants' learning motivation in online classes. Active participants are taking steps to improve the environment, manage study time, and seek assistance. Based on these studies, we conclude that learners' achievement in the online learning is attributed to both intrinsic and extrinsic motivations.

Students with high motivation are more likely to engage in demanding tasks, participate actively in activities, and yet appreciate and adopt a deep learning approach, as seen by their performance, tenacity, and originality (Schunk et al., 2008). Participating and interacting with others in a learning environment, completing tasks on time, always doing their best at work, and enjoying the learning process are examples of how motivation affects learning (Gardner, 2006; Brophy, 2010). Some studies (Tseng \& Tsai, 2010; Shin, 2010; Chaiprasurt \& Esichaikul, 2013; Xu \& Du, 2013; Xie \& Huang, 2014; Alkis \& Temizel, 2018, Ginting et al., 2021) reveal that intrinsic and extrinsic motivation affect the participants' performance in online programs.

MOOC is a one of the representations of multimedia-based learning. According to Cognitive Load Theory (CLT), students effectively learn new information if media are designed following human's limited working memory capacity (Sweller, 2004; Sweller, 2005). Effective media help students learn, integrating new relevant information with their schema to reconstruct knowledge (Sweller et al., 1990; Sweller \& Chandler, 1994; Sweller, 2004). Effective media should adhere to multimedia learning principles such as coherence, signaling, contiguity, segmenting, multi-modality, personalized principles (Moreno \& Mayer, 2000; Mayer, 2001).

Coherence is a principle emphasizing that multimedia design must contain relevant instruction content (Moreno \& Mayer, 2000). Unrelated information must be eliminated to allow working memory to process the information. Good quality multimedia focuses on important information by anticipating additional information on the same learning material. Thus, the media has adhered to the redundancy principle (Mayer \& Moreno, 2010).

Several techniques, such as text-based cues (italics, bold, underline), picture-based cues, and vocal cues, represent the principle of signaling that directs students' attention to the important information. This activity leaves more capacity for generative processing, leading to meaningful learning outcomes (Sweller, 2005). Moreover, multimedia also must accommodate agronomic presentations of the learning contents. These techniques are called contiguity principles. To help learners understand the materials well, the texts should be spatially adjunct with the visual presentations. In the same way, aligning narrated explanations with the on screen presentation temporally is also necessary to avoid learners' confusion (Mayer \& Moreno, 2010).

The segmenting approach enables the students to learn at their desired pace when discovering new content. They move through their own speed and digest information at their own rate (Mayer \& Moreno, 2010). It enables students to be engaged in necessary information processing without absorbing their limited working memory capacity. Instead of on-screen text, it is important to deliver words as speech (Mayer \& Moreno, 2010). Audio narration, grounded on 
this multi-modality principle, assists learners acquire new material more effectively than the on text, especially when the image is sophisticated, the words are unfamiliar, and the instruction is fast-paced and out of their control. The instructor in E-learning is an on-screen figure who engages with the student. On-screen figures known as pedagogical agents help guide students through the e-learning process (personalized principle).

\subsection{Research Questions}

The literature has widely discussed the study of MOOCs as a digital platform to promote learners' autonomy. This paper aims to examine how the quality of a MOOC program is related to the motivation of the online participants and which aspects the designers must pay attention to in developing an effective MOOC. The research question of this study is formulated as follows. How do MOOC participants complete the MOOC program? To what extent MOOC quality should be developed to become an effective online module?

\section{Method}

The MOOC was a collaborative project between two universities in Indonesia. Having prepared for non-academic university staff eager to improve their English proficiency, the MOOC was intended to help the university staff with their English so that they can effectively communicate with international students regarding administration issues, such as course admissions, timetabling, scheduling, and heading up academic and general briefings, and organizing departmental events.

\subsection{Study Setting}

The MOOC comprised four modules designed to help the participants with reading skills, writing skills, and vocabulary mastery, using various non-literary or informational texts. The orientation webinar session preceded the MOOC. This session aimed to help the participants familiarize themselves with the rules, the contents of MOOC, and Moodle navigation tools as MOOCs learning management system. To get a certificate of completion from this MOOC program, participants must take a pre-and post-test, complete all assignments in four modules, and achieve a passing score (70).

Module One, entitled the Model of the Conversation, aims to help them with reading strategies such as skimming and scanning. Module Two, entitled University Management, should help participants with contextual guessing techniques. The MOOC introduces linguistic and contextual clues to the participants to make sense of unfamiliar vocabulary in various informational texts. Module 3 was about problems at work and ways to cope with them. The aim of this module should promote the participants with active thinking readers through applying critical reading and thinking skills. The participants were encouraged to practice their analytical, interpretative, and evaluative skills. Module Four, entitled Working with Technology, taught the participants how to prepare emails and social media using English.

MOOC is a pilot program whose aim is to test the quality of the MOOC program before being widely disseminated to other participants outside the host universities. For this reason, the authors only involved ninety-five university administration staff as participants in the MOOC pilot project. After the MOOC ended, seven participants did not participate. Meanwhile, twenty-one staff took part in this program, which only scored below seventy. Thus, only sixty-seven could complete the MOOC program.

\subsection{Participants}

The cumulative assessments of the MOOC show that the achievement level of the MOOC participants vary, including ninety-six high score participants and seventy low scores participants. Based on the score distribution of the MOOC, it can be concluded that the participants were divided into three groups: high achievers (HA), middle achievers (MA), and low achievers (LA). Table 1 shows how these three groups are classified based on their score intervals. We purposely selected three participants to become the key informants: A (high achiever), B (mid achiever), and $\mathrm{C}$ (low achiever).

Table 1. Participant Achievement

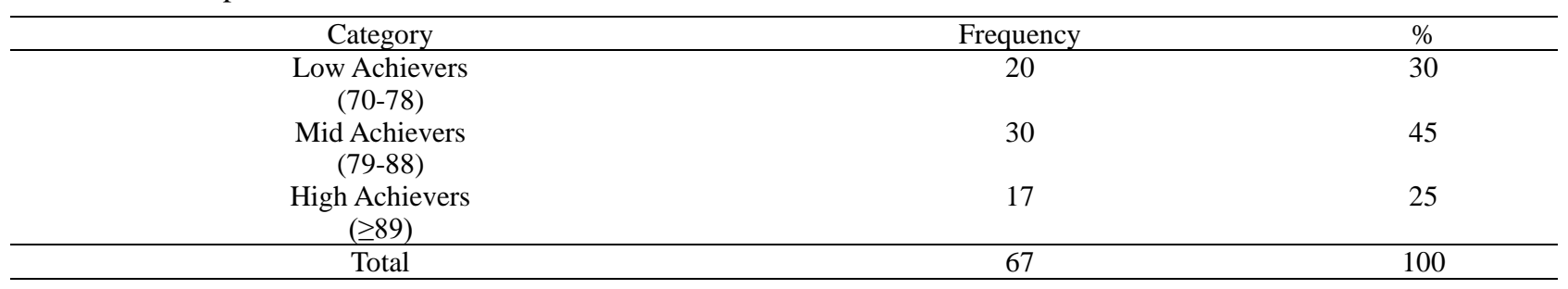


For ethical considerations, the authors paid attention to the informed consent procedure. Before the research was carried out, the researchers had held a meeting with the participants. We ensured that the subject had fully comprehended the information of the research. We provided ample opportunities for them to ask questions. We exchanged ideas until we succeeded in obtaining the subject's voluntary agreement to participate. To ensure the participants' privacy, we have disguised their names using pseudonyms in this paper.

\subsection{Data Gathering Procedure}

The checklist instrument was adopted and adapted from Huang and Hew (2016) to measure the participant motivation. This checklist comprises four dimensions: attention (12 items), relevance ( 9 items), confidence ( 9 items), and satisfaction (6 items). Overall, there were thirty-six items. Table 2 shows the motivational levels of the participants, starting from low to high. Each item has a different weight, starting from 1 (strongly disagree), 2 (disagree), 3 (agree), and 4 (strongly agree). Before conducting the interview, the researchers informed these three respondents to fill out the checklist. The data collection process was quite effective as they filled out all the questions from this checklist online.

Table 2. Motivation Categories

\begin{tabular}{lc}
\hline \multicolumn{1}{c}{ Motivational Category } & Scores \\
\hline High & $3.23-4.0$ \\
Upper medium & $2.48-3.22$ \\
Medium & $1.80-2.47$ \\
Low & $1.0-1.70$ \\
\hline
\end{tabular}

To reinforce the validity of the data, the researchers conducted the online interview. Using a guided interview, the key informants got a clear explanation about the procedures of the interview. The authors used open-ended questions that allowed the participants to provide information that did not restrict the participants' opinions (Creswell \& Clark, 2011).

The authors analyzed interview data using the following procedures: data logging, data coding, and thematic networks. The authors gathered the data from the interview (Khan, 2008; Easterby-Smith et al., 2008). The authors used coding to provide labels or codes to different areas of text that were relevant to specific topics. According to Creswell (2007), coding is the process of fracturing and categorizing text to provide meanings and themes in data. With the use of a coding system, it intends to minimize data by classifying the data transcripts into manageable and relevant transcript portions. In the topic network, the authors plan to conduct a theme analysis of qualitative data. Major themes are the database's most important ideas, while minor themes are the database's secondary ideas. A web-like network organizational principle is used in the implementation of the theme network. It explains the steps used from text to interpretation.

This study used an analytical rubric to assess the quality of the MOOC program. It contains several items that contain some principles of the cognitive load theory of multimedia learning. Each item from the rubric has a rating scale ranging from 1 (poor), 2 (sufficient), and 3 (good). Several aspects of the checklist include modality (visual and auditory material), contiguity, redundancy, segmentation, and personalization. The authors assigned four experts to assess the quality of the MOOC using the rubric. The participants went through an integration process to get unanimous decisions in assessing the MOOC quality.

\subsection{Data Gathering Procedure}

\section{Pre-and post-tests}

This MOOC required the participants to take pre and post-test. The authors gave the participants the pre-test before the MOOC. Both pre and post-tests had the same test items: the participants had to complete vocabulary mastery tests from 1000-words to 5000-words levels. The authors developed the text in a multiple-choice format. They informed the participants to complete the test in thirty-five minutes.

The pre-test and post test data were analyzed using the paired-sample t-test using SPSS version 16. From Table 3, the sig value. (2-tailed) is 0.391, the authors conclude no significant difference between the pre-test and the post-test mean regarding vocabulary mastery. These results indicate MOOC does not significantly improve the online participants' vocabulary mastery. However, the participants still gained benefits from the MOOC. They have learned reading, writing, analytical, interpretative, and evaluative skills. This study found that $70 \%$ of the ninety-five participants completed MOOCs. 
Table 3. The results of paired sample t-test on pre-test and post-test

\begin{tabular}{|c|c|c|c|c|c|c|c|c|c|}
\hline \multicolumn{10}{|c|}{ Paired Samples Test } \\
\hline & & \multicolumn{5}{|c|}{ Paired Differences } & \multirow{3}{*}{$\mathrm{T}$} & \multirow{3}{*}{ Df } & \multirow{3}{*}{$\begin{array}{c}\text { Sig. } \\
\text { (2-tailed) }\end{array}$} \\
\hline & & \multirow{2}{*}{ Mean } & \multirow{2}{*}{$\begin{array}{c}\text { Std. } \\
\text { Deviation }\end{array}$} & \multirow{2}{*}{$\begin{array}{l}\text { Std. Error } \\
\text { Mean }\end{array}$} & \multicolumn{2}{|c|}{$\begin{array}{l}\text { 95\% Confidence Interval of } \\
\text { the Difference }\end{array}$} & & & \\
\hline & & & & & Lower & Upper & & & \\
\hline $\begin{array}{c}\text { Pair } \\
1\end{array}$ & $\begin{array}{l}\text { Pretest - } \\
\text { posttest }\end{array}$ & 3.05263 & 21.68565 & 3.51788 & -4.07526 & 10.18053 & .868 & 37 & .391 \\
\hline
\end{tabular}

\section{Findings and Discussions}

\subsection{Motivation}

The authors have identified that $70 \%$ of the participants completing the MOOC had high motivation to learn independently, as shown by our three key informants: a high achiever (HA), a mid-achiever (MA), and a low achiever (LA) (see Table 4). They actively take part in the learning environment, complete the tasks in time, enthusiastically perform their best effort, and enjoy their learning process (Gardner, 2006; Brophy, 2010). HA has relatively the English proficiency much better than MA and LA. Meanwhile, MA and LA have to work much harder to study and complete MOOC assignments.

Table 4. The motivational aspects of HA, MA, and LA

\begin{tabular}{ccccc}
\hline $\begin{array}{c}\text { Key } \\
\text { informant }\end{array}$ & Attention & Relevance & Confidence & Satisfaction \\
\hline HA & 3.5 & 3.7 & 3.4 & 3.8 \\
MA & 4 & 3.8 & 3 & 3.6 \\
LA & 3.9 & 4 & 4 & 3.6 \\
\hline
\end{tabular}

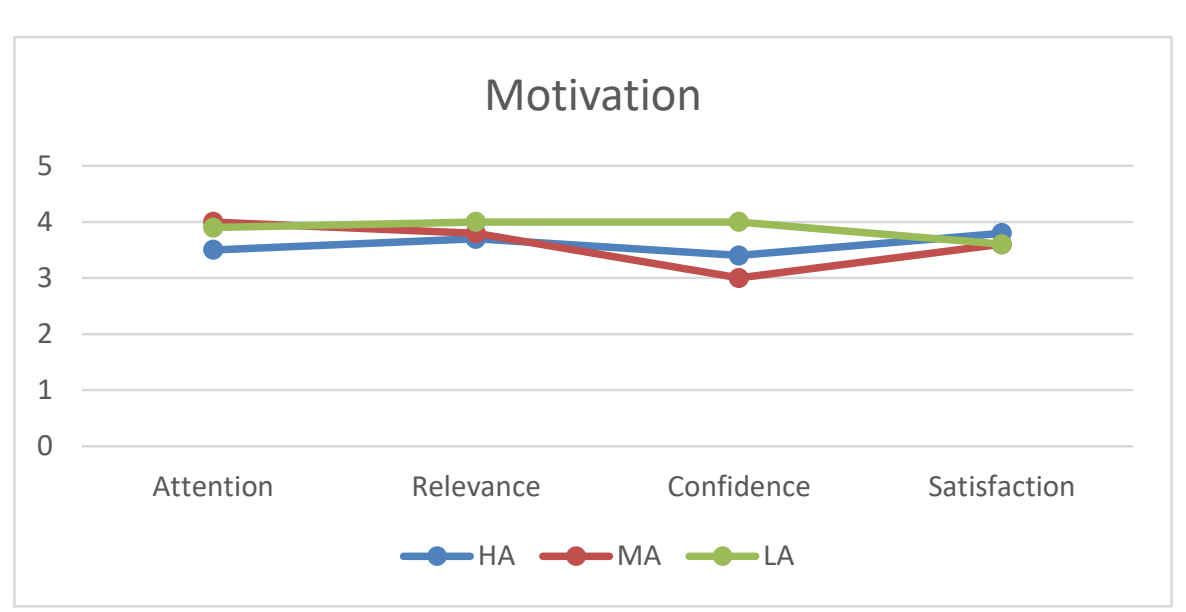

Figure 1. motivation aspects

\subsubsection{Attention}

HA has better English proficiency than MA and LA. She admits that she could learn materials from the MOOC better than other MOOC participants. Moreover, she could also identify her own weaknesses during the MOOC program. This issue is shown in excerpts $1,2,3$, and 4.

\section{[Excerpt 1]}

I tried many times to do the assignment and take some photos using my mobile phone on the particular parts of the instruction and the questions. I learned again until I found out the answers. Then I am inquisitive about the following questions that may differ from the last time... I make posters and videos for the projects. It is like an animated PowerPoint (ppt). (HA) 


\section{[Excerpt 2]}

...I searched the information on YouTube about the conversation. I searched for some papers from a journal to enhance my reading skill. (LA)

My score is rather low, I will try harder again, but the result is the same. I need to learn more about vocabulary. I have a shortage of vocabulary, so it is difficult for me. (LA)

\section{[Excerpt 3]}

I also use another application, namely Fillmore for doing the project since I cannot use the application. There are some parts that I cannot finish because the question is tough. That is why I am late to submit it. I ask about my friends' work, then I learn and learn again. (LA)

[Excerpt 4]

I directly registered myself in the MOOC program to train and enhance my English skill. ...I learn about 'skimming' and do some vocabulary tests. I feel the MOOC program is proper and an excellent program for me. (MA)

Most respondents (89.3\%) or about fifty-four students (54) were found to prefer a fully online class to blended learning (see Table 2). The preference of the majority of respondents was strongly affected by social agents such as their parents and social media. (MA)

MA and LA (excerpts 2, 3, and 4) focus on the efforts they have made and the lack they have felt. MA and LA realized the MOOC program got their attention, so they registered for the program previously and tried their best to learn through the services. MA and LA work harder since they want to do the same thing as others. That is why MA and LA work much more complicatedly and feel attracted to do the MOOC assignment more to improve their English. This evidence explains why MA and LA scored the attention aspect slightly larger than HA. What HA does in her criticism is to show the parts of MOOC that should be improved later on. That is why HA gives a score that differs slightly from MA and LA. Those participants' descriptions and scores show that the quality of MOOC is well categorized in some specific parts. Based on this investigation, the authors can infer that there should be an improvement in media features in MOOCs. Chaiprasurt and Esichaikul (2013) mention that the media has a tremendous influence in encouraging students' motivation to learn online specifically to gain their attention and engagement variables

\subsubsection{Relevance}

The three respondents (HA, MA, and LA) considered that the initial information about MOOCs attracted their attention to register. When they found the initial information about this MOOC on the internet, they immediately registered. According to them, the theme and purpose of this MOOC apply to their needs as education administration personnel who need reading, writing, and vocabulary skills related to administrative affairs on campus.

\section{[Excerpt 5]}

I joined the MOOC program because I am interested in English, and I want to enhance my English. I am lacking in speaking and the others, so I joined some courses previously and this MOOC. (MA)

\section{[Excerpt 6]}

I got new vocabulary when joining any courses, such as IELTS and TOEFL iBT, including MOOC

(HA).

Before joining MOOC, they had attended several non-formal English training programs at several course centers. In addition, as undergraduate graduates, they have also taken English courses while still studying at university. However, they admit that their English proficiency is relatively low, so they improved their English skills through this MOOC. HA, for example, works as a laboratory in a university that has many international students. Communicating with those international students, such as helping to prepare laboratory equipment and scheduling practice, are routine tasks that he does every day. This routine with high international students is a powerful incentive for HA to improve his English proficiency. HA is not only familiar with English but also familiar with digital media. 
This phenomenon also occurs in Alkis and Temizel's (2018) investigation that students who have strong self-efficacy and are familiar with LMS will have high motivation in online learning. Thus, these phenomena show the importance of being familiar with English and digital media.

Unlike HA, MA and LA work in universities where meeting and communicating with international students is relatively minimal. However, they insisted on joining the MOOC because their superiors often asked them to make reports in English. MA, for example, are employees who work in research and community service institutions. He has a regular duty to coordinate with funding institutions to propose and report on research activities on campus. LA, who works as a laboratory worker, must propose the purchase of laboratory equipment. Not infrequently, he has to correspond with sellers who are abroad.

\subsubsection{Confidence}

The respondents (HA, MA, LA) believe that MOOC programs improve their confidence, which is shown from their score in the confidence category (there is no score under 3). This finding shows that they are confident after joining a MOOC program. LA gets the more considerable impact of the MOOC program rather than those of MA and HA. LA has become more confident after joining MOOC. Previously, LA had many weaknesses that influenced her low confidence before joining MOOC.

Nevertheless, after joining MOOC, LA got a significant change in her confidence in implementing her English. Previously, LA was afraid of making mistakes when communicating with other people and always thinking about grammar when speaking. LA gives more significant confidence than HA and MA since LA's confidence gets more significant changes than HA and MA.

\section{[Excerpt 7]}

\section{Sometimes, I understand what people are saying. However, I rather doubt my grammar when responding to people who talk to me. (LA)}

Based on the excerpt, LA shows her weaknesses in terms of confidence before joining MOOC. This respondent believed that her confidence has increased. Here, LA confirms she gives a high score toward MOOC quality in terms of confidence category for its influence on her confidence level changes. Meanwhile, HA and MA who are more proficient in English, have higher confidence levels than LA before joining the MOOC program. HA and MA have low confidence levels (before and after joining MOOC). In comparison, LA starts from unconfident to confident (before and after joining MOOC), LA gets a lot in terms of his confidence level. LA gives a higher score on MOOC quality than those HA and MA because MOOC programs influence this LA's confidence a lot compared with HA and MA.

\section{[Excerpt 8]}

I am glad when I get new vocabulary, since my English vocabulary is still limited. Sometimes, I forget some of them. For example, I forgot some vocabulary when Thailand's interviewer interviewed me.

\section{[Excerpt 9]}

\section{I do the assignment several times to get the best result. I learn and learn again until I find out the answer and am satisfied with my efforts. I am curious about the following questions. (HA)}

What HA and MA focus on is to deal with the materials (vocabulary) and the questions. They have minor problems regarding their confidence when starting a MOOC program; they only have problems with vocabulary and materials to explore more. These matters show that these respondents have higher confidence before and after joining the MOOC program. Since HA and MA have high confidence before joining MOOC, the changes in their confidence level after joining the MOOC program are not significant. Their confidence level is stable before and after joining MOOCs. Therefore, HA and MA considered that MOOC programs affect their confidence, but not as high as LA because they were already confident before joining the MOOC program. HA and LA believe that MOOC programs have some effects on their confidence so that there is no score under 3 (Good) in the confidence category of MOOC. Thus, MOOC affects HA and MA's confidence and affects LA, which shows MOOC program is suitable for any level learners and impactful for low-achiever learners. MOOC can be an external stimulus that supports participants' autonomy, which leads to more autonomy and forms individual motivation. This condition can promote motivation 
(Deci \& Ryan, 1985).

\subsubsection{Satisfaction}

Based on previous categories (attention, relevance, and confidence), HA considers those categories to score slightly lower than MA and LA. Interestingly, HA considers higher scores in the Satisfaction category than those of MA and LA. These matters indicate MOOC programs satisfy HA at overall aspects in MOOC program. HA is more critical than those MA and LA in several aspects for the improvement of MOOC programs. HA considers MOOC programs as satisfying as a whole and criticizes at several points for more advanced improvement. Although HA has higher consideration than MA and LA regarding the satisfaction category, MA and LA still have identical scores with HA's in terms of satisfaction. This thing portrays that all three respondents (HA, MA, LA) have considered that MOOC programs give them satisfaction in almost all aspects. This satisfaction (motivation aspect) is undoubtedly related to the value of the course, interest in the course's services, self-determination, and autonomous regulation (Shin, 2010).

\section{[Excerpt 10]}

\section{I am so glad I completed the assignment. Since I chose this program, it has encouraged me to do my best to fulfill my choice. (HA)}

\section{[Excerpt 11]}

I learn about reading techniques, namely skimming, some vocabulary, and my understanding of the materials. My speaking is better than before. So, I feel that joining the MOOC program is a brilliant choice for me. (LA)

The most critical aspect that triggers HA to consider MOOC programs as satisfaction services is its challenge. HA is glad of her achievement after completing the assignment and overcoming the challenge that she has faced. The MOOC program encourages HA to do its best in English training. HA feels self-satisfaction after overcoming the challenge, finding the answer, and doing all assignments by herself. These descriptions portray the MOOC program encourages HA to be an autonomous learner since it challenges HA to do the assignment by herself. The authors relate this phenomenon to Garcia and Pintrich (1996), who believe that e-learning behaviours mainly refer to autonomous behaviour or the ability to regulate self-initiative. Meanwhile, MA and LA mainly satisfy MOOCs regarding reading skill, vocabulary exercises, and their perception of the services provided by the MOOC program.

Respondents' satisfaction with MOOC programs shows that those respondents (HA, MA, LA) have been motivated to learn more about English in MOOC programs. The evidence is that the respondents choose MOOC program by themselves, complete all assignments even though there are some difficult questions, find out learning sources from YouTube, websites, and other sources to answer the questions, strive to try again when they have failed, find out another way to understand the instructions and state their pride and satisfaction on what they have done in MOOC program. What HA, MA, and LA have done are in line with Dörnyei (2001) that motivation as a 'process whereby a certain amount of investigation force arises, initiates action, and persists as long as no other force comes into play to weaken it and end the action, or until the planned outcome has been reached. That evidence shows that participants' high motivation during and after joining MOOC impacts their learning goals (Improving their English). Concerning this matter, Schunk et al. (2008) believed that motivation is a process of action consistently directed towards achieving goals. Despite some weaknesses, the authors use it as input to improve a particular section in the MOOC program.

Based on respondents' perception of overall motivation (attention, relevance, confidence, and satisfaction), MOOC's contents and services motivate them (HA, MA, LA) during and after joining the program. Motivation levels among HA, MA, and LA are slightly almost the same; they only have minor differences in particular aspects, such as the challenge and learning strategies in MOOC programs. Those high motivation respondents show MOOC is impactful toward their paced-learning and skills development. This finding aligns with Gardner (2006), who believed that students with high motivation have better performance than students with low motivation. The present study is also in line with other investigations (Garcia \& Pintrich, 1996; Kim and Frick 2011; Ginting et al., 2021) that motivation during self-directed e-learning is the best predictor of "positive change in motivation", which predicts learner satisfaction with self-directed e-learning. Thus, MOOCs can be alternative long-distance learning to encourage students' motivation and English skills. 


\subsection{The Quality of the Course}

Based on the participants' perception of the quality of the MOOC course, the quality of overall aspects of MOOC's services affects their learning. A well-prepared instructional program design makes it easy for participants to learn and thus motivates them to study hard. In the perspective of the cognitive load of multimedia learning theory, instructional programs must be designed as effectively as possible according to the way the human brain operates. Due to limited memory capacity, instructional design must be prepared based on the following principles: presenting all relevant information content (coherence), avoiding the similar information input (redundancy), emphasizing important things (signaling), presenting concise material (segmenting), ensuring consistency between the visual display and narrated audio (contiguity), introducing to pre-training, and utilizing visual and auditory input (multi-modality) to deliver instructions. These principles are a prerequisite for being encoded in long-term memory. Because of the limitation of working memory, the learner must choose which information from sensory memory to pay attention to during the learning process. Thus, the design of instructional materials, including MOOC, should be prepared based on how human brains work.

The MOOC has instructional videos to help participants learn English for academic staff at universities. This instructional video is recognized as a powerful medium that can provide narrative visualization and engage multiple student senses simultaneously. For example, participants could use multiple functions like play, pause, and stop, which can help learners to enrich their notes on the topic. These features allow students to learn at their own pace. They can watch the video if they do not understand the instructors' explanation. Some of the weaknesses of MOOC are seen in terms of redundancy and pre-training, which are closely related to instructional videos. The quality of the MOOC is shown in Figure 2. This figure shows that the quality of the MOOC has weaknesses in some areas such as redundancy and pre-training.

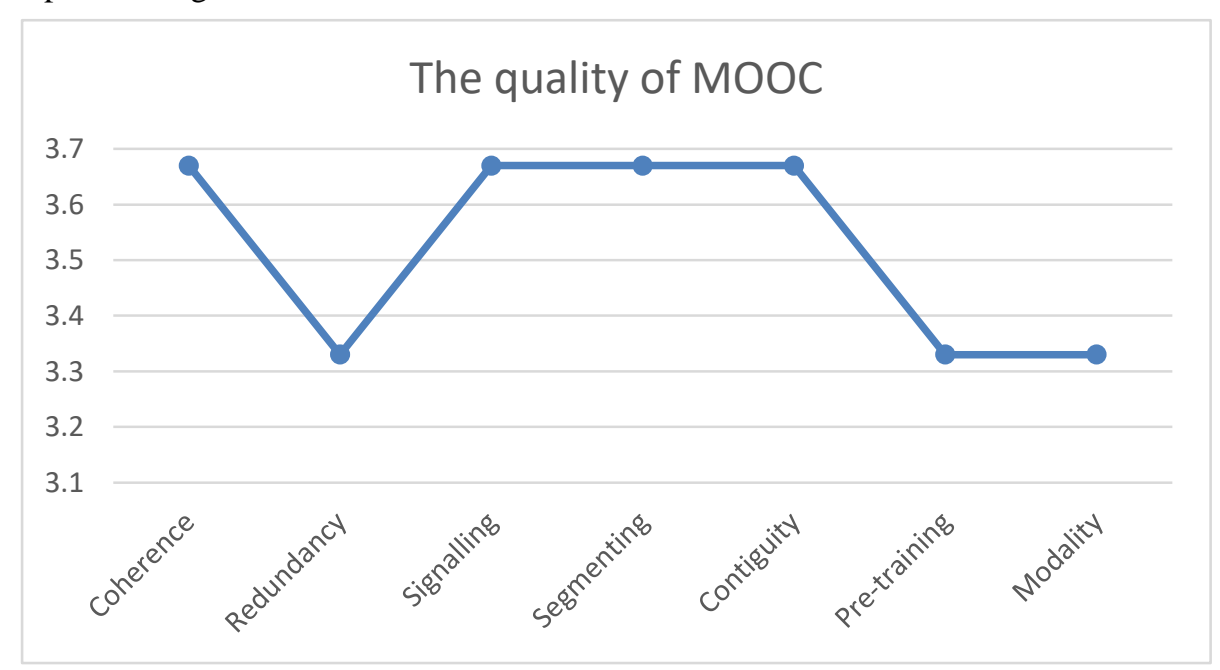

Figure 2. The quality of MOOC's services

The instructional videos introduced at the beginning of each MOOC module are often inserted with subtitles, word-for-word translations of dialogue. The developer believes that this caption guides participants to important points during the instructors' presentations. For example, in Module 1, when the instructor is explaining reading strategies such as skimming and scanning, the caption appears multiple times with the text. The example caption contains keywords like Skimming, Scanning, How to Scan, How to Skim. Although at the same time the lecturer gave an explanation on the same topic in addition to a PowerPoint with the same information. The same cases of redundancy appear in the instructional videos in other modules.

Based on the redundancy principle, adding captions to the video is considered redundant. Students need to pay attention to the caption, which contains superficial information. Thus, they split their attention by paying attention to the caption, the text and instructor's explanation. In reality, students are learning quicker whenever motion graphics and narration are provided separately from written text than when they are offered simultaneously with written words (Mayer, 1997; Mayer, 2001; Mayer \& Moreno, 2003). According to the redundancy effect, an animated/illustrated and annotated presentation of instructional video content has a greater beneficial impact on the learning process than an animated/illustrated and annotated presentation with subtitles or other written text. 
However, other studies have shown that captions have a positive effect on students' learning quality. For example, Linebarger (2001) found that videos' audio and captions helped students focus on important information on a lesson topic. Adegoke (2010) found that students who studied with the animation + narration + caption got higher scores than those with the animation + narration. Perez et al. (2013) and Winke et al. (2010) concluded that captioned videos greatly influence listening comprehension and vocabulary in foreign language teaching. From the results of this study, the authors conclude that the principle of redundancy must be handled carefully. Meanwhile, captions or other additional features such as animation or text can turn into an unfavorable extrinsic load that hinders learning (Moreno \& Mayer, 2000; Mayer \& Moreno, 2010). However, instructors can take advantage of the caption feature to improve the quality of learning if they use it appropriately and not excessively.

Some modules of the MOOC are tricky for participants who are still at a beginner level of English proficiency. The MOOC has many advanced vocabulary and even long reading texts which make it difficult to learn the MOOC modules and complete the assignments. As a result, many participants had given up on completing the MOOC. Providing material relevant to the participant's skill level is essential. The difficulty of this MOOC material content represents an intrinsic load, draining the participants' cognitive energy to learn. Before studying the module, participants with low English proficiency must be assisted with basic knowledge related to the MOOC module material through pre-teaching.

Pre-teaching allows beginners to read through a text, answer questions, or study vocabulary before the module begins. The participants need to be given extra time and attention to understand the subject matter several times: through pre-teaching and during the completion of MOOC modules. Vocabulary lists are the most common form of pre-teaching that helps English language learners prepare for an upcoming lesson. The instructor gives the participants a list of words that need to be used in the upcoming modules. The participants study the words so that they can use them in the modules.

The multimodality aspect is an important issue that MOOC developers pay attention to. The multimodality principle means that quality learning occurs when participants learn with media that provide a combination of audio and visuals (Sweller \& Chandler, 1994), such as videos. Videos enabled participants to remember information well because they used both sensory channels (ears and eyes) to retain cognitive information and avoid overloading. Some videos on the MOOC generally contain introductory parts of the modules. For example, the instructor provides general information about the module, its objectives, and schedule. Meanwhile, to understand the essence of the module itself, the participants had to look for it by reading long texts in e-books and websites. Reading text means only relying on textual modality. Reading long texts is not a big problem for participants with advanced English proficiency, but it is not the case with beginner English proficiency. Long texts overload participants' visuals, making them difficult to learn. As a result, they might feel bored. They undergo cognitive overload (Sweller, 2005). Multi-modality is essential for those with a low knowledge background (Mayer \& Moreno, 2010). The modules in the MOOC should be presented in the form of videos with little sharing of textual material.

[Excerpt 12]

In the beginning, sometimes I was confused because it was a new thing for me. I have to scroll the information up and down... However, I understand at the end after reading it many times. The pictures and other media are still synchronous with the information and instruction in MOOC. (HA)

[Excerpt 13]

The visual appearance and the narration are still synchronous. The picture is helpful to identify what the narration means. So, in the beginning, I observed the picture to know what had been written. (LA)

[Excerpt 14]

This program is a new thing for me. So, I tried to imagine the procedure based on the existing information. Even if it is very new for me, it challenged me to learn what it is and how to do it by

$$
\text { myself. (LA) }
$$

Viewing from signaling, segmenting, and contiguity principles, MOOC modules already have quality program design qualities. For example, the structure of all modules from MOOC has been arranged in a neat, consistent, and orderly manner. For example, each module is highlighted with subtitles such as module name, materials, discussion, 
and assignments (quiz and projects). This information signals participants to pay attention to important things and manage time to study. Thus, the modules of the MOOC have been segmented into several sections. This technique helps the participants who are still beginners to focus on the essence (Sweller et al., 1990; Sweller \& Chandler, 1994). Concerning the contiguity principle, the MOOOC provides the participants with consistent in-time feedback that the MOOC instructors have given.

In many cases, the participants got consistent feedback from other members or MOOC instructors in the discussions. The instructors agreed with the participants about a particular day where they gave feedback on the discussion task. By knowing the clarity of this schedule, participants know when they have to do assignments and receive feedback. Therefore, they know to whom they must discuss or ask for help (Sweller et al., 1990; Sweller \& Chandler, 1994).

\section{Conclusions}

A MOOC allows learners to practice the materials and obtain knowledge independently. They can improve their English mastery since this online platform offers specific, fast, accessible, meaningful learning activities - intrinsic and extrinsic factors play significant roles in learners' motivation in learning online modules. Moreover, the quality of MOOCs is another essential factor to help participants in the learning process. The MOOC should be carefully designed, allowing learners to conveniently obtain meaningful information from the media. The convenient display of MOOC, whose design is adhered to how the brain process the information, promotes meaningful learning: ensuring relevant content, presenting visual and auditory in sync, highlighting critical information to help learners shift attention to the essence, providing segmented material to make it easier for learners to digest new information, and delivering lessons using simple language and easy to understand. Regardless of their level of achievement, the online instructors must maintain learners' motivation through their active participation in the online learning: giving quick and appropriate feedback, helping slow learners with pre-teaching, etc. Therefore, the interplay of motivation and the quality of the online platform is essential in determining the success of online learning.

\section{References}

Adegoke, B. A. (2010). Integrating animations, narratives and textual information for improving Physics learning. Electronic Journal of Research in Educational Psychology, 8(2), 725-748.

Alkis, N., \& Temizel, T. T. (2018). The impact of motivation and personality on academic performance in online and blended learning environments. Educational Technology \& Society, 21(3), 35-47. Retrieved from https://www.jstor.org/stable/10.2307/26458505

Bandura, A. (1997). Self-efficacy: The exercise of control. W H Freeman/Times Books/ Henry Holt \& Co.

Barrett, L., Tudage, M., \& Engel, R. (2004). Individual differences in working memory capacity and dual-process theories of the mind, Psychological Bulletin, 130(4), 553-573. https://doi.org/10.1037/0033-2909.130.4.553

Brophy, J. (2010). Motivating students to learn (3rd ed.). Routledge. https://doi.org/10.4324/9780203858318

Chaiprasurt, C., \& Esichaikul, V. (2013). Enhancing motivation in online courses with mobile communication tool support: A Comparative Study. International Review of Research in Open and Distance Learning, 14(3), 377-401. https://doi.org/10.19173/irrodl.v14i3.1416

Chen, C. L. A. (2012). Extended implications of technology in second language teaching and learning. Teachers College, Columbia University Working Papers in TESOL \& Applied Linguistics, 11(2), 27-28. https://doi.org/10.7916/salt.v11i2.1390

Chun, D., Smith, B., \& Kern, R. (2016). Technology in language use, language teaching, and language learning. Modern Language Journal, 100, 64-80. https://doi.org/10.1111/modl.12302

Cowan, N. (2001). The magical number 4 in short-term memory: A reconsideration of mental storage capacity, Behavioural and Brain Sciences, 24(1), 87-114. https://doi.org/10.1017/s0140525x01003922

De Jong, T. (2010) Cognitive load theory, educational research, and instructional design: Some food for thought, Instructional Science, 38(2), 105-134. https://doi.org/10.1007/s11251-009-9110-0

Deci, E. L., \& Ryan, R. M. (1985). Intrinsic motivation and self-determination in human behavior. New York, NY: Plenum Press. https://doi.org/10.1007/978-1-4899-2271-7

Deci, E. L., Koestner, R., \& Ryan, R. M. (2001). Extrinsic rewards and intrinsic motivation in education: Reconsidered once again. Review of Educational Research, 71(1), 1-27.

https://doi.org/10.3102/00346543071001001 
Dörnyei, Z., \& Usjioda, E. (2010). Teaching and researching motivation (2nd ed.). Harlow, England: Routledge. Retrieved from https://www.routledge.com/Teaching-and-Researching-Motivation/Dornyei-Ushioda/p/book/9781408205020

Eccles-Parsons, J., Adler, T. F., Futterman, R., Goff, S. B., Kaczal, C. M., Meece, J. L., \& Midgley, C. (1983). Expectancies, values, and academic behaviors. In J. Spence, Achievement and achievement motivation, 75-146. San Francisco, California: Freeman.

Garcia, T., \& Pintrich, P. R. (1996). The effects of autonomy on motivation and performance in the college classroom. Contemporary Educational Psychology, 477-486. https://doi.org/10.1006/ceps.1996.0032

Gardner, R. C. (2006). The socio-educational model of second language acquisition: a research paradigm. Eurosla Yearbook, 6(1), 237-260. https://doi.org/10.1075/eurosla.6.14gar

Geary, D. (2012). Evolutionary educational psychology. In K Harris, S Graham \& T Urdan (Eds.), APA Educational Psychology Handbook. American Psychological Association, 1(1), 597-621. https://doi.org/10.1037/13273-020

Ginting, D., Djiwandono, P., Woods, R., \& Lee, D. (2020). Is autonomous learning possible for Asian students? The story of a MOOC from Indonesia. Teaching English with Technology, 20(1), 60-79. Retrived 20 July, 2021, from https://tewtjournal.org/volume-2020/issue-1/

Ginting, D., Fahmi, Y. B., Linarsih, A., \& Hamdani, B. (2021). Foreign language students' voices on blended learning and fully online classes during the COVID-19 Pandemic. World Journal of English Language, 11(2), 62-70. https://doi.org/10.5430/wjel.v11n2p62

Ginting, D., Woods, R., Nuswantara, K., Sukaton, O. Z., \& Jiuangga, V. V. (2021). Teachers' voice: their experiences in emergency remote teaching amid COVID-19 pandemic. Mextesol Journal, 45(4), 1-15. Retrieved from http://www.mextesol.net/journal/index.php?page=journal\&id_article $=25320$

Kim, K., \& Frick, T. (2011). Changes in student motivation during online learning. Journal of Educational Computing Research, 44(1), 1-23. https://doi.org/10.2190/EC.44.1.a

Lim, D. H. (2004). Cross-cultural differences in online learning motivation. Educational Media International, 41(2), 163-173. https://doi.org/10.1080/09523980410001685784

Linebarger, D. L. (2001). Learning to read from television: The effects of using captions and narration. Journal of Educational Psychology, 93(2), 288-298. https://doi.org/10.1037/0022-0663.93.2.288

Martens, R. L., Gulikers, J., \& Bastiaens, T. (2004). The impact of intrinsic motivation on e-learning in authentic computer tasks. Journal of Computer Assisted Learning, 20(25), 368-376. https://doi.org/10.1111/j.1365-2729.2004.00096.x

Martin, A. (2016). Using Load Reduction Instruction (LRI) to boost motivation and engagement. Leicester UK: British Psychological Society.

Mayer, R. E. (1997). Multimedia learning: Are we asking the right questions?. Educational Psychologist, 32(1), 1-19. https://doi.org/10.1207/s15326985ep3201_1

Mayer, R. E. (2001). Multimedia learning. New York, NY: Cambridge University Press. https://doi.org/10.1017/CBO9781139164603

Mayer, R. E., \& Moreno, R. (2003). Nine ways to reduce cognitive load in multimedia learning. Educational Psychologist, 38(1), 43-52. https://doi.org/10.1207/S15326985EP3801_6

Mayer, R. E., \& Moreno, R. E. (2010). Techniques that reduce extraneous cognitive load and manage intrinsic cognitive load during multimedia learning. In J. L. Plass, R. Moreno, \& R. Brunken, Cognitive Load Theory, 131-152. New York: Cambridge Press. https://doi.org/10.1017/CBO9780511844744.009

Moreno, R., \& Mayer, R. E. (2000). A coherence effect in multimedia learning: The case for minimizing irrelevant sounds in the design of multimedia messages. Journal of Educational Psychology, 92(1), 117-125. https://doi.org/10.1037/0022-0663.92.1.117

Perez-Liebana, D., Samothrakis, S., Togelius, J., Schaul, T., \& Lucas, S. (2016). General Video Game AI: Competition, Challenges and Opportunities. Proceedings of the AAAI Conference on Artificial Intelligence, 30(1). Retrieved January 12, 2021, from https://ojs.aaai.org/index.php/AAAI/article/view/9869

Rovai, A. P., Ponton, M., Wighting, M., \& Baker, J. (2007). A comparative analysis of student motivation in traditional classroom and e-learning courses. International Journal on E-Learning, 6(3), 413-432. Retrived 
from https://www.learntechlib.org/primary/p/20022/

Schunk, D. H., Pintrich, P. R., \& Meece, J. L. (2008). Motivation in education: theory, research, and applications (3rd ed.). Upper Saddle River, N.J.: Pearson/Merrill Prentice Hall. Retrieved from https://searchworks.stanford.edu/view/6774934

Shin, T. (2010). Effects of providing a rationale for learning a lesson on students' motivation and learning in online learning environments. Michigan: Michigan State University. Retrieved from https://www.proquest.com/docview/816026378

Shroff, R. H., Vogel, D., Coombes, J., \& Lee, F. (2007). Student e-learning intrinsic motivation: A qualitative analysis. Communications of the Association for Information system, 19(1), 241-260. https://doi.org/10.17705/1CAIS.01912

Swan. K. (2005). A constructivist model for thinking about learning online. In J. Bourne \& J. C. Moore (Eds.), Elements of quality online education: Engaging communities. Needham, MA: Sloan-C.

Sweller, J. (2004). Instructional design consequences of an analogy between evolution by natural selection and human cognitive architecture. Instructional Science, 32(2), 9-31.

https://doi.org/10.1023/B:TRUC.0000021808.72598.4d

Sweller, J. (2005). The redundancy principle in multimedia learning. In R. E. Mayer (Ed.), Cambridge handbook of multimedia learning, 159-167. New York: Cambridge University Press. https://doi.org/10.1017/CBO9780511816819.011

Sweller, J., \& Chandler, P. (1994). Why is some material difficult to learn? Cognition and Instruction, 12(3), 185-233. https://doi.org/10.1207/s1532690xci1203_1

Sweller, J., Chandler, P., Tierney, P., \& Cooper, M. (1990). Cognitive load as a factor in the structuring of technical material. Journal of Experimental Psychology: General, 119(1), 176-192. https://doi.org/10.1037/0096-3445.119.2.176

Tricot, A., \& Sweller, J. (2014). Domain-specific knowledge and why teaching generic skills do not work, Educational Psychology Review, 26(2), 265-283. https://doi.org/10.1007/s10648-013-9243-1

Tseng, S., \& Tsai, C. C. (2010). Taiwan college students' self-efficacy and motivation of Learning in Online Peer Assessment Environments. Internet and Higher Education, 13(3), 164-169. https://doi.org/10.1016/j.iheduc.2010.01.001

Wighting, M. J., Liu, J., \& Rovai, A. P. (2008). Distinguishing sense of community and motivation characteristics between online and traditional college students. Quarterly Review of Distance Education, 9(3), 285-295. Retrived July 22, 2021, from https://www.proquest.com/docview/231200398?fromopenview=true\&pq-origsite=gscholar

Winke, P., Gass, S., \& Sydorenko, T. (2010). The effects of captioning videos used for foreign language listening activities. Language Learning \& Technology, 14(1), 65-86. Retrived January 11, 2022 from http://riset.unisma.ac.id/index.php/jp3/article/view/3873

Xie, K., \& Huang, K. (2014). The role of beliefs and motivation in asynchronous online learning in college-level classes. Journal of Educational Computing Research, 50(3), 315-341. https://doi.org/10.2190/EC.50.3.b

Xiong, J., \& Zuo, M. (2019). Older adults' learning motivations in massive open online courses. Educational Gerontology, 45(2), 82-93. https://doi.org/10.1080/03601277.2019.1581444

Xu, K., \& Du, J. (2013). Regulation of motivation: Students' motivation management in online collaborative group work. Teachers College Record, 115(10), 10-25. https://doi.org/10.1177/016146811311501006

Zhao, C., \& Mei, Z. (2016). A case study of American and Chinese college students' motivation differences in the online learning environment. Journal of Education and Learning, 5(4), 104-112. https://doi.org/10.5539/jel.v5n4p104

\section{Copyrights}

Copyright for this article is retained by the author(s), with first publication rights granted to the journal.

This is an open-access article distributed under the terms and conditions of the Creative Commons Attribution license (http://creativecommons.org/licenses/by/4.0/). 